\title{
Evaluation of the Action of Chelating Agents on the Microhardness of Superficial Layer of Root Canal Lumen Dentin
}

${ }^{1}$ Bandu Devrao Napte, ${ }^{2}$ SR Srinidhi

\begin{abstract}
Aim: To evaluate the effect of different chelating agents on the microhardness of the superficial dentin layer of the root canal lumen.

Materials and methods: Forty-two extracted single rooted teeth were instrumented, and the roots were longitudinally sectioned in a buccolingual direction to expose the entire canal extension. The specimens were randomly distributed in four groups according to the final irrigation: Glyde File Prep (Dentsply Maillefer, Ballaigues, Switzerland), RC Help (Prime Dental Pvt. Ltd, Mumbai, India), Endo Prep RC (Stedman Anabond, Chennai, India), Dolo Endogel (Prevest Denpro Ltd, Jammu, India). A standardized volume of $50 \mu \mathrm{l}$ of each chelating agent was used for 5 minutes. Dentin microhardness was measured with a Knoop indenter under a $50 \mathrm{gm}$ load and a 15 seconds dwell time. Data was analyzed statistically by one-way analysis of variance ANOVA and post hoc multiple-comparison test at $5 \%$ significance level.
\end{abstract}

Results: Statistically significant difference was detected among the chelating agents by one-way ANOVA. Glyde File Prep and Dolo Endogel chelating agents differed significantly $(p<0.0001)$ in reduction of dentin microhardness from RC help and Endo Prep RC.

Conclusion: Glyde File Prep and Dolo Endogel are significantly better than RC Help and Endo Prep RC in reducing dentin microhardness.

Keywords: Chelating agents, Dentin microhardness, EDTA, Knoop indenter.

How to cite this article: Napte BD, Srinidhi SR. Evaluation of the Action of Chelating Agents on the Microhardness of Superficial Layer of Root Canal Lumen Dentin. World J Dent 2014;5(2):124-128.

Source of support: Nil

Conflict of interest: None

\section{INTRODUCTION}

Root canal instrumentation consists of combined action of endodontic instruments and irrigating solutions, aiming at the elimination of pre-existent organic and inorganic remnants or debris resulting from the operative procedures as well as the reduction of the microbial content and its

${ }^{1}$ Postgraduate Student, ${ }^{2}$ Professor

1,2Department of Conservative Dentistry and Endodontics Sinhgad Dental College and Hospital, Pune, Maharashtra, India

Corresponding Author: SR Srinidhi, Professor, Department of Conservative Dentistry and Endodontics, Sinhgad Dental College and Hospital, Pune, Maharashtra, India, e-mail: srinidhi73@yahoo.com byproducts. ${ }^{1}$ An irrigating solution should present a number of physicochemical properties in order to be effective in endodontics. It is known, however, that no endodontic irrigant presents all ideal properties and, thus, the combination of auxiliary solutions is necessary to achieve the desired effects. The chances of success in the endodontic therapy increase as debris and smear layer are removed. It is believed that removing this layer could dissolve attached microbiota and their toxins from root canal walls, improve the seal of root fillings, and reduce the potential of bacterial survival and reproduction.

Sodium hypochlorite $(\mathrm{NaOCl})$ is the most widely used chemical solution in the biomechanical preparation of the root canal system, and it has been used in endodontics in concentrations ranging from 0.5 to $5.25 \%$. However, despite its excellent antimicrobial action and capacity of dissolving organic materials, this solution alone does not effectively remove the smear layer, and its association with chelating agents that act on organic matter is necessary. ${ }^{1}$

The term 'Chelate' originates from the Greek word 'Chele' (crab claw). Chelates are particularly stable complexes of metal ions with organic substances as a result of ring shaped bonds. ${ }^{1}$ The demineralizing effect of chelators acts both on the smear layer and the root dentin, with consequent exposure of collagen and decrease of dentin microhardness. ${ }^{2}$ Chelating agents were introduced to endodontics by Nygaard-Østby in 1957 as an aid for the preparation of narrow and calcified root canals. ${ }^{3}$ The use of chelating agents during biomechanical preparation of root canals removes smear layer, increases the access of the irrigant into the dentin tubules to allow adequate disinfection, and reduces dentin microhardness, facilitating the access and action of endodontic instruments in narrow, calcified root canals.

A liquid solution of EDTA was the first chelator used in dentistry as an agent capable of chemically softening the root canal dentin, dissolving the smear layer and increasing dentin permeability. EDTA is also available in range of 15 to $17 \%$ in gel form.

It has been studied that evidence of mineral loss or gain of dentin can be estimated by microhardness determination. ${ }^{4}$ In vitro studies investigating the effect of chelating agents on dentin microhardness have traditionally used dentin disks 
cut transversally from roots of bovine ${ }^{2}$ or human teeth. ${ }^{3,5} \mathrm{It}$ has been shown that the irrigating solution diffuses through the dentin tubules from the main root canal to a distance of up to $1500 \mu \mathrm{m}$ toward the root cementum., ${ }^{2,6}$ During canal irrigation, the solution initially has direct contact with the most superficial dentin layer of the root canal lumen and then diffuses through the tubular root dentin structure. To simulate the clinical situation, this study evaluated the action of chelating agents by irrigating the main canal with the test solution and then measuring the microhardness of the most superficial layer of dentin of the root canal lumen using a methodology in which the roots were split longitudinally. ${ }^{7}$ There have been numerous products available in the market, each claiming better chelating efficacy while performing cleaning and shaping. The aim of this study was to evaluate the effect of commonly available gel chelating agents RC Help (Prime Dental, Mumbai, India), Endo Prep RC (Anabond Stedman Pharma Research, Chennai, India), Dolo Endogel ( Prevest Denpro, Jammu, India) on the microhardness of the most superficial layer of dentin of the root canal lumen and to compare their reduction in microhardness with Glyde File Prep (Dentsply, USA).

\section{MATERIALS AND METHODS}

\section{Materials}

EDTA solutions used were:

1. Glyde File Prep (Dentsply Maillefer, Ballaigues, Switzerland) $-15 \%$ EDTA and $10 \%$ urea peroxide in aqueous solution and Glycol base.

2. RC Help (Prime Dental Products Pvt Ltd, Mumbai, India) - 17\% EDTA, 8\% Carbamide peroxide, 75\% Glycol.

3. Endo Prep RC (Anabond Stedman Pharma Research Ltd, Chennai, India) - EDTA- $15 \%$ w/w and Carbamide peroxide- $10 \% \mathrm{w} / \mathrm{w}$.

4. Dolo Endogel (Prevest Denpro Ltd, Jammu, India) — 17\% EDTA buffered to neutral $\mathrm{pH}, 10 \%$ Carbamide peroxide, purified water with silica as thickening agent, $1 \%$ Sodium hypochlorite.

5. Rotary Endodontic Protaper System (Dentsply Maillefer, Ballaigues, Switzerland).

6. $3 \%$ Sodium Hypochlorite (Hyposept, UPS Hygienes Pvt Ltd, Mumbai, India).

\section{Methods}

\section{Biomechanical Preparation of the Root Canals}

Forty two extracted single-rooted teeth were selected and stored in $0.1 \%$ thymol solution. The teeth were decoronated at the cementoenamel junction with a water-cooled diamond saw and cervical preflaring was done with Gates Glidden drills (Mani, Japan). The working length (WL) was established with a size $10 \mathrm{~K}$-file (Dentsply Maillefer, Ballaigues, Switzerland) introduced into each root canal until its tip was visualized at the apex and then pulled back $1 \mathrm{~mm}$. The anatomic diameter of the canal at the WL was also checked by introducing K-type instruments of successively larger diameters, and the instrument that showed resistance on removal from WL was recorded. Nickel-titanium rotary system (Protaper, Dentsply) was employed for cleaning and shaping according to a crown-down technique. During preparation, the root canals were irrigated with $2 \mathrm{ml} \mathrm{3 \%}$ sodium hypochlorite at each change of file with an irrigation time of 30 seconds for each flush. A final irrigation with $20 \mathrm{ml} 3 \%$ sodium hypochlorite was performed for the removal of possible dentin chips.

\section{Specimen Preparation}

Grooves were prepared along the long axis of the roots with a water-cooled diamond disk mounted on a highspeed handpiece, and the same was used to cleave the roots longitudinally in a buccolingual direction to expose the entire canal extension (Fig. 1A). The convex surface of the half covered with cementum was flattened with a diamond cylindrical abrasive point (Mani, Japan) mounted on a highspeed handpiece to maintain a minimal thickness of $2 \mathrm{~mm}$ between the abraded surface and the root canal lumen. The dentin layer between the canal lumen and the cementum was also abraded at an angulation of approximately $45^{\circ}$ to facilitate the polishing of root canal lumen dentin and its visualization in the microhardness tester (Fig. 1B). ${ }^{13}$ During the whole preparation phase, abrasion of the root segment was performed under an operative microscope at $8 \times$ magnification (Moller Wedel, Germany) to increase the accuracy of preparation.

Each specimen was attached to a dental plaster block with adhesive (Fig. 2) and the block sets were randomly assigned to four groups of ten teeth each according to final irrigating solution:

Group I-Glyde File Prep, group II-RC Help, group IIIEndo Prep RC, group IV-Dolo Endogel, group V-control (no irrigation).

\section{Treatment of the Specimens}

A standardized volume of $50 \mu \mathrm{l}$ of each chelating agent (Fig. 3) was delivered directly on root canal dentin to fill the whole canal extension. After 5 minutes, the specimens were rinsed with $20 \mathrm{ml}, 3 \%$ sodium hypochlorite to remove any residue of the test solution. 


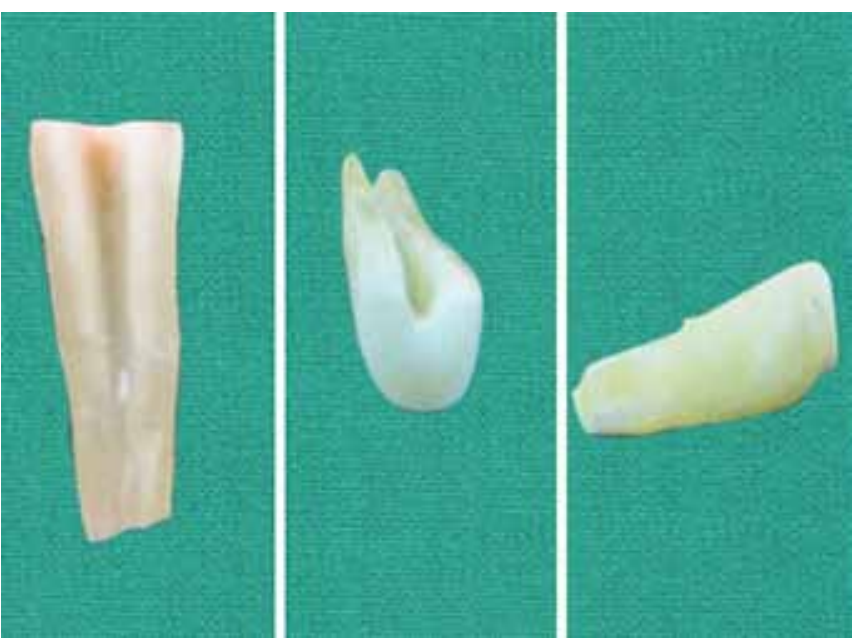

Fig. 1A: Sectioned specimens

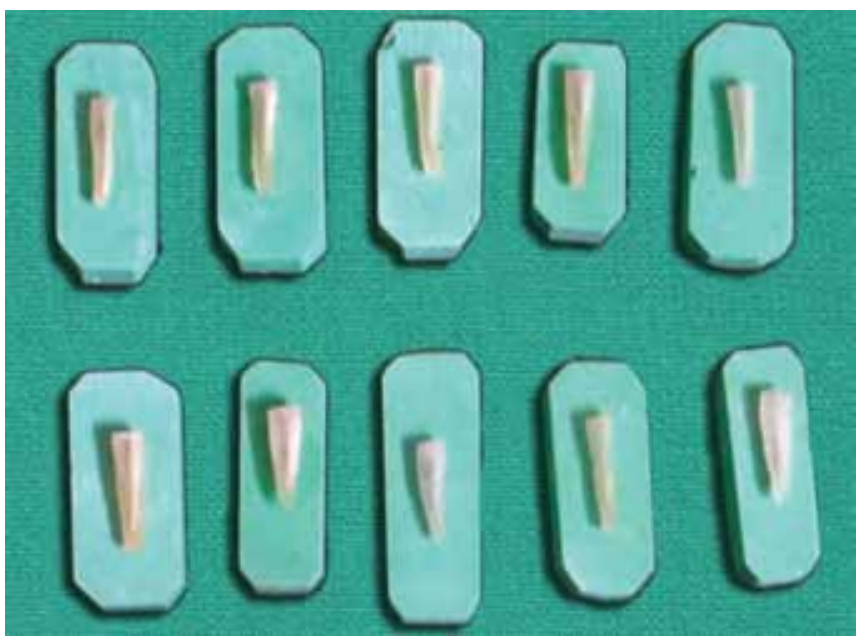

Fig. 2: Mounted specimens

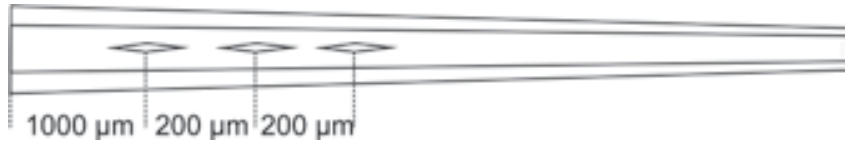

Fig. 4A: Knoop indentations on the root canal lumen dentin

\section{Microhardness Measurements}

Dentin microhardness was measured with a Knoop indenter at $\times 40$ magnification (Reichert, Austria) under a $50 \mathrm{gm}$ load and a 15 seconds dwell time. In each sample, three indentations were made along lines parallel to the edge of the root canal lumen (Fig. 4A). ${ }^{13}$ The first indentation was made $1000 \mu \mathrm{m}$ from the root canal entrance and two other indentations were made at a distance of $200 \mu \mathrm{m}$ from each other. The average lengths of the two diagonals were used to calculate the microhardness value (Fig. 4B). The representative hardness value for each specimen was obtained as the average of the results for the three inden-

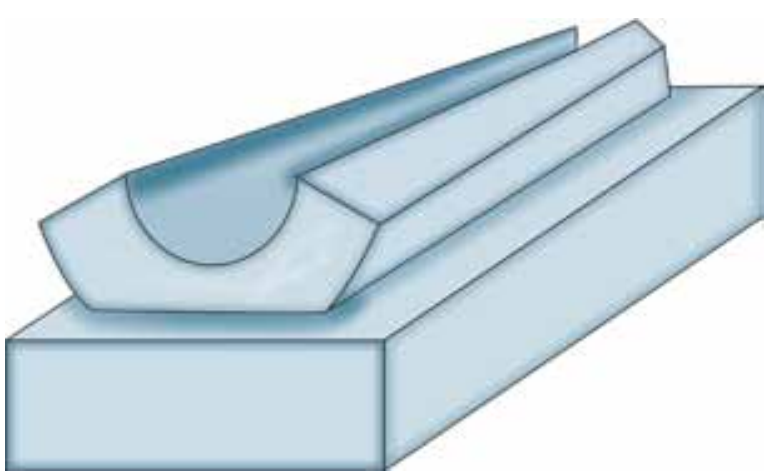

Fig. 1B: Bevelling of the sectioned specimen

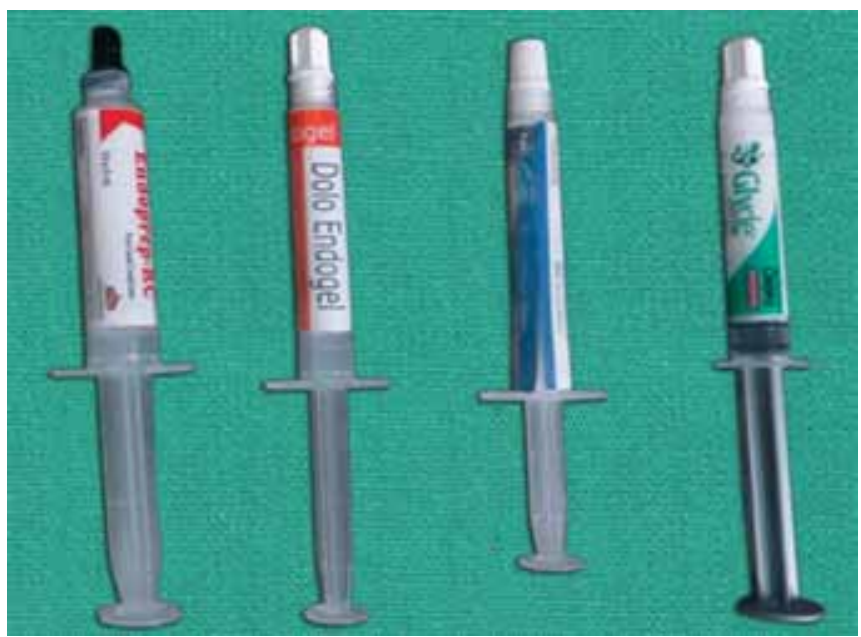

Fig. 3: Chelating agents

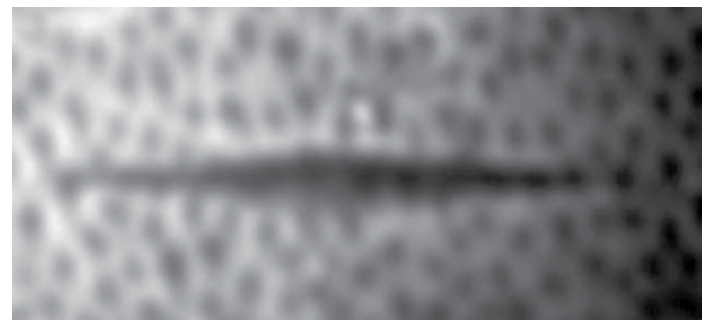

Fig. 4B: Indentation on root canal dentin

tations. Data was analyzed statistically by one-way ANOVA and the post hoc multiple-comparison test. A significance level of 5\% was set for all analyses.

\section{RESULTS}

The Knoop microhardness values (mean \pm SD) for the chelating agents are summarized in Table 1 . The value in each table row corresponds to the average of three measurements in ten different specimens for a total of 30 measurements. Statistically significant difference was detected among the chelating agents by one-way ANOVA $(p<0.0001)$. Glyde File Prep and Dolo Endogel had the 
Table 1: Mean microhardness values of each group

\begin{tabular}{llllll}
\hline Specimen no. & $\begin{array}{l}\text { Control group } \\
(K H N)\end{array}$ & $\begin{array}{l}\text { Group I } \\
\text { (Glyde File Prep) } \\
(K H N)\end{array}$ & $\begin{array}{l}\text { Group II } \\
(\text { RC help) } \\
(K H N)\end{array}$ & $\begin{array}{l}\text { Group III } \\
\text { (Endo Prep RC) } \\
(K H N)\end{array}$ & $\begin{array}{l}\text { Group IV } \\
\text { (Dolo Endogel) } \\
(K H N)\end{array}$ \\
\hline 1 & 66.19 & 53.21 & 59.89 & 56.71 & 51.91 \\
2 & 64.47 & 56.2 & 61.61 & 55.82 & 57.9 \\
3 & 54.32 & 55.44 & 56.2 & 55.82 \\
4 & 61.59 & 57.79 & 57.89 & 56.2 \\
5 & 55.1 & 56.67 & 56.8 & 54 \\
6 & 52.33 & 58.51 & 57.77 & 56.63 \\
7 & 53.57 & 56.57 & 56.79 & 54.37 \\
8 & 51.8 & 58.5 & 57.53 & 55.08 \\
9 & & 57.2 & 56.09 & 53.79 \\
10 & 57.27 & 59.33 & 57.87 & 56.1 \\
Average & 52.48 & 58.93 & 56.93 & 55.18 \\
\hline
\end{tabular}

Table 2: Statistical analysis

\begin{tabular}{llllll}
\hline Groups & No. of samples & Mean & SD & $\begin{array}{l}p \text {-value of } \\
\text { one-way } \\
\text { ANOVA }\end{array}$ & Post hoc test \\
\hline 1 & 10 & 54.787 & 2.96288 & & 1 and $2=0.004^{*}$ \\
2 & 10 & 58.151 & 1.81679 & $0^{* *}$ & 1 and $3=0.124 \#$ \\
3 & 10 & 56.937 & 0.76331 & & 1 and $4=0.991 \#$ \\
4 & 10 & 55.18 & 1.71532 & 1 and $5=0^{* *}$ \\
5 (control) & 2 & 65.33 & 1.21622 & 2 and $3=0.640 \#$ \\
& & & & 2 and $4=0.014^{*}$ \\
& & & & 2 and $5=0^{* *}$ \\
& & & 3 and $4=0.283 \#$ \\
& & & 3 and $5=0^{* *}$ \\
$4=p<0.01(\mathrm{~S}) ;{ }^{* *}=p<0.01(\mathrm{HS}) ; \#=p>0.05$ (NS) $5=0^{* *}$
\end{tabular}

greatest overall effect, causing a sharp decrease in dentin microhardness without statistically significant difference between them ( $p>0.05)$. However, Glyde File Prep and Dolo Endogel differed significantly from RC help and Endo Prep RC groups. Mean and standard deviation was calculated. Data was subjected to statistical analysis using SPSS v17 software (Chicago, Ill, USA). One-way ANOVA was used for inter-group comparison, followed by post hoc test for pair-wise comparison (Table 2).

\section{DISCUSSION}

Dentin has phosphate and calcium which is soluble in water. The hardness value of unaffected dentin is between 40 and $75 \mathrm{~kg} / \mathrm{sq} \mathrm{mm} .{ }^{8}$ When disodium salt of EDTA is added to this equilibrium, $\mathrm{Ca}^{2+}$ is removed from the solution. This leads to further dissolution of ions from dentin so that solubility product remains constant. This mechanism is used by chelators to cause dentin decalcification. ${ }^{1}$ Neutral or alkaline $\mathrm{pH}$ of EDTA causes optimum dentin decalcification. ${ }^{9}$ All of the products tested had $\mathrm{pH}$ in the ideal range.
EDTA acts efficiently in the reduction of dentin microhardness because of its chelating property. Several theories have tried to explain this chemical reaction. According to the crystalline field theory, the attraction force between the central metal and the ligands is purely electrostatic. Therefore, the attraction force exerted by the metallic ion is greater than the repulsive force offered by the atoms of the EDTA molecule. ${ }^{1}$ Chelators such as EDTA form a stable complex with the calcium ions in dentin. At this time, carboxyl groups of the EDTA molecule are ionized, releasing hydrogen atoms that compete with the calcium ions. ${ }^{1}$

The reducing effect of EDTA on dentin microhardness has been reported by Sayin et al. ${ }^{10}$ They verified that EDTA alone or followed by $2.5 \% \mathrm{NaOCl}$ promoted a significantly greater decrease in dentin microhardness. Pawlicka ${ }^{11}$ reported that chelators can change the root dentin hardness by about 20 Vickers hardness number. The greatest differences are to be found in the dentin immediately adjacent to the root canal lumen. In our study, we found that the most superficial layer of root canal lumen dentin was the most affected due 
to the action of the chelators. This has a bearing on the biomechanical preparation in that the infected dentin in the superficial layer of the root canal can be removed with the endodontic instrumentation more easily after the use of these chelating agents.

Studies have been done to estimate the time needed for chelation. Most of them agree that good cleaning efficiency of EDTA is seen with working times of 1 to 5 minutes. ${ }^{9,12}$ In our study, we have kept the EDTA in contact with the root canal dentin for 5 minutes which is a more realistic time in terms of clinical practice.

A previous study evaluated the microhardness of superficial and deep dentin using Knoop and Vickers hardness tests. ${ }^{13}$ It was found that Knoop hardness test efficiency was significantly higher for superficial than for deep dentin. Its chief character is its sensitivity to surface texture of dentin. It is also less sensitive to measurement errors while estimating the length of the longest diagonal. In our study, three indentations were done on the surface of the superficial dentin at different distances and the average of the three was taken to eliminate errors.

Dolo Endogel showed significantly better reduction in dentin microhardness when compared to RC Help and Endoprep RC and equivalent to Glyde File Prep. This could be due to the presence of $10 \%$ carbamide peroxide and $1 \%$ sodium hypochlorite as studies have shown use of EDTA and sodium hypochlorite has better action on the dentin surface. ${ }^{5}$ The thickening agent of silica present may increase the contact time of the solution to the dentin surface. It shows promise as a chelating agent with effective reduction in dentin microhardness comparable to Glyde File Prep.

Further studies are needed wherein the effect of liquid and gel forms of EDTA are compared. The microstructure of the treated dentin can be evaluated at various levels apart from the most superficial layer using more advanced spectroscopic methods. The nanohardness of the treated dentin can be estimated at various depths of the dentin which will give a more accurate picture of the effect of EDTA.

\section{CONCLUSION}

All tested chelating agents showed reduction of the microhardness of the most superficial layer of dentin of the root canal lumen. However, Glyde and Dolo Endogel are significantly better than RC Help and Endo Prep RC in reducing dentin microhardness.

\section{REFERENCES}

1. Hulsmann M, Heckendorff M, Lennon A. Chelating agents in root canal treatment mode of action and indications for their use. Int Endod 2003;36(12):810-830.

2. Slutzky-Goldberg I, Maree M, Liberman R, Heling I. Effect of sodium hypochlorite on dentin microhardness. J Endod 2004;30(12):880-882.

3. De-Deus G, Paciornik S, Mauricio MHP. Evaluation of the effect of EDTA, EDTAC and citric acid on the microhardness of root dentine. Int Endod J 2006;39(5):401-407.

4. Arends J, Ten Bosch JJ. Demineralization and remineralizationevaluation techniques. J Dent Res 1992;71(4):924-928.

5. Cruz-Filho AM, Sousa-Neto MD, Savioli RN, Silva RG, Vansan LP, Pecora JD. Effect of chelating solutions on the microhardness of root canal lumen dentin. J Endod 2011;37(3):358-362.

6. Saleh AA, Ettman WM. Effect of endodontic irrigation solutions on microhardness of root canal dentine. J Dent 1999;27(1):43-46.

7. Patterson S. In vivo and in vitro studies of the effect of the disodium salt of Ethylene diamine tetra acetate on human dentin and its endodontic implications. Oral Surg Oral Med Oral Pathol 1963;16: 83-103.

8. Calt S, Serper A. Time dependent effects of EDTA on dentin structures. J Endod 2002;28(1):17-19.

9. De-Deus G, Zehnder M, Reis C, Fidel S, Fidel RAS, Galan J Jr, Paciornik S. Longitudinal co-site optical microscopy study on the chelating ability of etidronate and EDTA using a comparative single tooth model. J Endod 2008;34(1):71-75.

10. Sayin TC, Serper A, Cehreli ZC, Otlu HG. The effect of EDTA, EGTA, EDTAC and tetracycline hydrochloride with and without subsequent sodium hypochlorite treatment on the microhardness of root canal dentin. Oral Surg Oral Med Oral Pathol Radiol Endod 2007;104(3):418-424.

11. Pawlicka H. Verwendung der Chelatverbindungen zur Erweiterung der Wurzelkanale: Mikroharteuntersuchung. Stomatologie der DDR 1982;3:355-361.

12. Hulsmann M, Heckendorff M. Comparative evaluation of three chelator pastes. Int Endod J 2002;35(8):668-679.

13. Fuentes V, Toledano M, Osorio R, Carvalho RM. Microhardness of superficial and deep sound human dentin. J Biomed Mater Res A 2003;66(4):850-853. 